\title{
EL PERSONAJE DEL «AMIGO» EN LA NOVELA GRIEGA ANTIGUA. DE JENOFONTE DE EFESO A AQUILES TACIO
}

Máximo Brioso Sánchez

Recientemente hemos publicado un artículo que, bajo el título «El personaje del 'amigo' en la novela griega. Caritón» ${ }^{1}$, supone, de un lado, un detenido análisis de la figura de Policarmo en la novela de Caritón y, de otro, un planteamiento del método que creemos más adecuado para un estudio de este tipo, con una amplia aplicación, y a la vez la promesa de continuar el mismo análisis en el resto de las novelas griegas conservadas. En las páginas que aquí siguen se cumple una segunda etapa de esta promesa y, aunque es lógico que nos permitamos remitir a aquel trabajo previo para una plena información del lector sobre el modo en que tratamos el tema y sus resultados parciales, también entendemos que puede ser útil y hasta cierto punto necesario hacer ahora un resumen de lo más esencial de aquel primer examen, por esquemático que sea. Los puntos principales son los siguientes:

A) La novela griega ofrece por lo general pero con ciertas variantes dos polos de entidad fuertemente contrastada: uno, el círculo familiar (familia, lugar natal, «patria»), como reflejo y reducción del ámbito de la antigua comunidad político-social; otro, el mundo de las peripecias y desdichas de los protagonistas y sus posibles acompañantes a través de una geografía ajena y peligrosa. Esta división tajante parece simbolizar la crisis creciente de la sociedad helenísticoimperial. El amor de los protagonistas y algunos otros vínculos como el de la lealtad del «amigo» representan lazos que, en plenas peripecias, unen con aquel otro 
polo de estabilidad y dicha, es decir, el círculo natal y familiar. De ahí la importancia del personaje del «amigo», por lo general sin embargo muy descuidado por los estudiosos de la novela griega antigua.

B) El método seguido en esta indagación rehuye abstracciones y formalismos. Una vez recogida toda la información posible que el propio texto nos proporciona, se han elaborado dos catálogos, en parte complementarios: uno, de motivos, de carácter más dinámico y referido tanto a las diversas actuaciones del personaje como a aquellas de que él mismo es objeto; otro, de atributos, de carácter por tanto más estático, en que se enumeran calificaciones, descripciones, etc. del «amigo», así como ciertos aspectos de dimensión más típicamente literaria.

a) Los motivos catalogados son los siguientes ${ }^{2}$ :

- Compañía voluntaria y (casi) constante del héroe.

- Impedimento (repetido) del suicidio del héroe.

- Consuelo (repetido) del héroe.

- Estímulo a la acción; también a un nuevo amor.

- Sacrificio abnegado.

- Testimonio (en juicio).

- Engaño (beneficioso) del héroe; también de otros personajes.

- Colaboración en una empresa.

- Sustitución en el mando.

- Emparejamiento con el héroe.

- Objeto de elogio (por lealtad, por servicio a la patria).

- Recepción de recompensa ${ }^{3}$.

b) Los atributos se dividen en dos categorías:

Positivos:

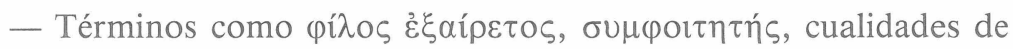
hombre de bien, reflexivo, decidido, abnegado, hábil (con inclusión de la capacidad de engaño), más ciertas calificaciones sociales que, aunque con vacilaciones en el texto, dan a Policarmo el status de libre pero de rango quizás inferior al del protagonista Quéreas ${ }^{4}$.

- Centro (eventual) del relato.

- Narrador (eventual).

- Personaje-enlace.

Negativos:

2 Los términos en cursiva corresponden a los que se han utilizado y se utilizarán también aquí como claves o referencias abreviadas. Este procedimiento nos parece extremadamente cómodo, más desde luego que los socorridos sistemas de siglas.

3 Emparejamiento no ha de ser confundido con la simple compañia: significa que en determinado momento el «amigo» actúa a la par del héroe (o en su caso, de otro personaje, que se especificaría) y así se expresa de algún modo en el texto. Supone por tanto una dignificación, si se trata de un personaje secundario como el «amigo». Podríamos haber establecido un apartado de motivos pasivos, sobre todo con elogio y recompensa, pero esta subdivisión no añadiría metodológicamente ninguna clarificación de importancia.

4 En el art. cit. discutíamos este punto, un tanto contradictorio en el texto de Caritón. Y añadíamos que el autor en cierto modo corregía esta imprecisión con el capítulo de las recompensas, al situar entonces a Policarmo en un status social superior definitivamente. 
- Vacío biográfico, descriptivo y erótico.

- Singularidad.

- Subordinación jerárquica.

- Eclipsamientos eventuales ${ }^{5}$.

C) Tras un concienzudo examen, de ambos catálogos se deduce básicamente que el «amigo» en Caritón, a pesar de su aparente y en parte real esquematismo, es un personaje bien diferenciado del resto de los «auxiliares»y muy en concreto del tipo del sirviente ${ }^{6}$; que, además de «amigo» leal y en exclusiva del héroe masculino del relato y de actuar sólo en función de los intereses de éste (su premio son elogios y recompensas), con plena subordinación jerárquica por tanto, es no obstante un personaje de cierta riqueza sicológica, al menos para el nivel usual en Caritón, así como de cierta importancia narrativa (según sus atributos como centro, narrador y enlace principalmente), subrayada por su singularidad, pero con la contrapartida de un vacío total en aspectos como el de su propia biografía personal ${ }^{7}$, la descripción física y sus tendencias eróticas, con el agravante de los eclipsamientos, en algunos casos realmente muy notables. Una cuestión capital es su relación, prácticamente negativa, con la heroína Calírroe y asímismo su casi

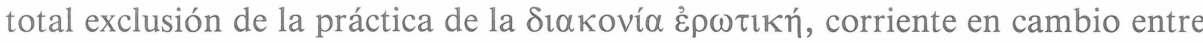
los auxiliares sirvientes ${ }^{8}$. En resumen y según allí concluíamos, en la figura del «amigo» en el novelista Caritón hay una importante dimensión social, un perfil más complejo de lo que suele decirse y creerse y una «esfera de acción» variada, en la que seguramente están en germen los desarrollos posteriores del tipo en los demás novelistas.

Entrando ya directamente en el tema en la novelística posterior a Caritón, comenzaremos nuestro análisis, siempre sobre las premisas metodológicas aplicadas a aquél, por el texto de Jenofonte de Efeso ${ }^{9}$. El cual, como veremos de in-

5 Centro implica una actuación relevante y autónoma en un episodio; narrador, que naturalmente cuenta (o informa narrando); enlace, que vincula a dos personajes entre sí: en Caritón IV 2 s. se dan simultáneamente estos tres atributos, al ser Policarmo protagonista de un episodio, informar narrando a Mitrídates acerca de ciertos antecedentes y conectar a Mitrídates con Quéreas. Singularidad equivale lógicamente a no pluralidad del personaje (no hay otro «amigo» que Policarmo en Caritón); subordinación significa que el personaje está condicionado narrativamente por otro, en este caso por Quéreas; eclipsamientos son lo mismo que olvidos por parte del autor: un personaje presente en un episodio no es mencionado, lo cual puede responder a un hecho de economía narrativa o a minusvaloración del personaje por el autor, o naturalmente a ambas causas a la vez.

6 Del cual lo distingue además claramente una barrera social. Caritón es en este punto muy cuidadoso.

7 Naturalmente antes y después de los hechos relatados en la novela. El autor no considera pertinente dar información complementaria sobre el personaje, lo que puede deberse a razones semejantes a las del eclipsamiento.

8 Sólo en VIII 1,6 Policarmo roza el delicado oficio de intermediario erótico. Por supuesto en ese episodio hay que distinguir la intención del «amigo» (estímulo a un nuevo amor) y las consecuencias en la trama.

9 El orden (cronológico) de los novelistas aquí adoptado es el que más comúnmente se acepta: Caritón, Jenofonte, Longo, Aquiles Tacio y Heliodoro. Por lo demás, damos por no demostrado que el texto de Jenofonte de Éfeso sea un resumen del original. 
mediato, a pesar de partir del modelo de Caritón, según suele aceptarse, introduce profundos cambios en el tratamiento del personaje del «amigo», revelando con ello también una categoría, en la inventiva al menos, superior a la que generalmente suele reconocérsele. Jenofonte está siempre dispuesto a crear situaciones complejas, a reiterar y multiplicar episodios y tipos, con una abierta anticipación de la técnica del folletín, y la figura del «amigo» participa de lleno de tales novedades. Técnicamente, tal como las enfocamos nosotros, algunas de estas innovaciones son de gran interés, ya que rompen estrepitosamente los sobrios esquemas (o mejor, esquematismos) de Caritón y dan lugar a nuevas y ricas posibilidades para la historia posterior de la novela griega.

La figura privilegiada del «amigo» es de nuevo en Efesíacas un joven, el bandido Hipótoo ${ }^{10}$, pero las notas constitutivas del personaje desbordan las del modelo Policarmo y, además, parece sufrir la competencia no ya sólo de otros personajes secundarios en su función corriente de «auxiliar», sino también muy concretamente de otro tan particular como es el pescador Egialeo. El papel del «amigo» en Jenofonte adquiere una autonomía y una personalidad propia a lo largo del relato y su contraste con Policarmo es bien significativo. Por lo que no debe sorprender que algunos críticos ${ }^{11}$ lo consideren incluso el personaje de mayor lucimiento de toda la novela.

Estudiaremos primero sus motivos y luego sus atributos, tal como hicimos con Policarmo.

Respecto a los motivos, la compañía se inicia en el encuentro de Hipótoo con Antía (II, 11, 11), justamente en el momento en que nos es presentado el «amigo» por primera vez en el texto y en el papel de «agresor» (véase después sobre este punto) de la heroína. Sólo más tarde se produce el primer encuentro con el héroe (II 14), al final del segundo libro, cuando ya han sucedido diversas peripecias. La compañía sólo ahora se manifiesta como voluntaria, tras ese fortuito encuentro, ya que es Hipótoo precisamente quien la propone al protagonista. En esa escena, entre las razones que Hipótoo alega para el proyecto de tal compañía hay una muy significativa, según el lector percibirá después: el lindo aspecto de

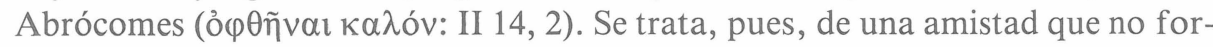
ma parte de una situación previa al inicio de la novela, a diferencia de lo que ocurre en Caritón, resultado de un encuentro fortuito e incluso motivada por razones muy concretas (la compasión y la valoración de los atractivos del héroe masculino) ${ }^{12}$. Ha de notarse además que la propuesta de Hipótoo es simplemente la

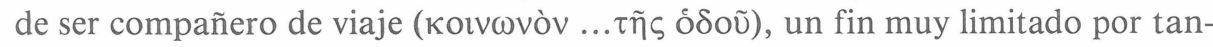
to, aunque esté en la base del papel tradicional del «amigo», y que Hipótoo se une al héroe tras faltarle a éste la compañía de la heroína-esposa. En apariencia

10 En su momento se tocará el tema de la «inmoralidad» del personaje, señalada ya por autores como F. Garin (Studi Italiani di Filologia Classica 17, 1909, pp. 423 ss.), el editor Dalmeyda y H. Gärtner (RE IX a 2, 1967, 207).

11 Así G. L. Schmeling, Xenophon of Ephesus (Boston, 1980), p. 83.

12 Respecto a la compasión citada no hay duda de que Jenofonte (un autor más sutil de lo que suele creerse) nos está remitiendo ya a la posterior autobiografía de Hipótoo, en que se cuentan sus trágicos amores. Hipótoo puede haber adivinado en Abrócomes un infortunio semejante al suyo. 
Jenofonte promete mantener una vinculación exclusiva de Hipótoo al héroe, como «amigo» al menos (dada su relación de partida con Antía, negativa), pero tampoco se atendrá a ello en absoluto. La compañía respecto a Abrócomes será pronto interrumpida y luego, en varias etapas, se tornará en una compleja relación Hipótoo -Antía. Hay, pues, una diversificación de este motivo, con una actuación doble de Hipótoo como «amigo», al ser vinculado a ambos protagonistas. Por otra parte, Hipótoo viaja de modo autónomo en varias ocasiones (así, al comienzo de IV, hacia Egipto, etc.) ${ }^{13}$, lo que tiene como consecuencia, entre otras, su ausencia en momentos de peligro del héroe, sobre todo en V 2, 6 y 2 , 9 , que son resueltos por la vía de la salvación milagrosa. Tales ausencias no representan, por supuesto, eclipsamientos, sino una insistencia en la autonomía del personaje, que a todas luces adquiere vida propia en Jenofonte. El distanciamiento narrativo de Hipótoo respecto a Abrócomes culmina en la estancia en Sicilia, cuando Hipótoo $(\mathrm{V}, 9,1)$ se casa: el autor, consciente de tal distanciamiento, lo hace en ese momento acordarse de Abrócomes $(\mathrm{V}, 9,2)$. El «amigo» ha dejado de ser una mera sombra del héroe, como lo era esencialmente Policarmo, adquiere un relieve mucho mayor en el relato y su relación con la protagonista femenina se hace más compleja y natural. Es más, Jenofonte incluso invierte el papel del «amigo» al convertirlo en auxiliar de la heroína en su búsqueda del héroe (V 9, 13, etc.). La constancia en la compañía se ha vuelto muy precaria y sólo en la parte final, desde el encuentro en Rodas, se regularizará. Por lo que resulta en este punto muy significativo que Abrócomes, lo que nunca hubiera podido hacer Quéreas en Caritón, pueda lamentarse (V 10,4) de que nadie ha sido partícipe de sus des-

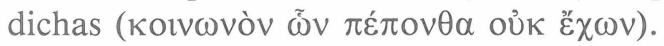

Frente al desarrollo y complicación del motivo de la compañía otros motivos muy concretos desaparecen: así, impedimento ${ }^{14}$, sacrificio ${ }^{15}$, testimonio, engaño (beneficioso) y sustitución. El motivo del consuelo también se diversifica, ya que se dirige tanto al héroe (III 3, 2) ${ }^{16}$ como a la heroína (V 9, 13). El estímulo está representado por la invitación al héroe a viajar con él (II 14,3), en el primer encuentro citado, habiendo desaparecido en cambio el estímulo erótico (hacia un nuevo amor) del que veíamos un conato en Caritón. En Jenofonte la capacidad

13 Naturalmente la autonomía de tales viajes ha de ser entendida en sus justos límites. En la novela griega todo está esencialmente subordinado a una sola acción principal; de ahí que, por ejemplo, ciertos viajes que aparecen como autónomos sean en realidad confluencias de los diversos personajes en lugares concretos: así hacia Egipto, como luego en el libro V hacia Rodas, o en Caritón la confluencia hacia Babilonia.

14 Abrócomes no representa ya un tipo de héroe tan desvalido como el Quéreas de Caritón (al menos en la primera parte de sus peripecias) y esto ha de influir en la desaparición o limitación de ciertos motivos. Así en el caso del impedimento, puesto que el único intento de suicidio de Abrócomes (II, 7, 1) le es impedido por la propia vigilancia a que es sometido en su prisión y no por el «amigo», ni siquiera presente aún en escena.

15 El único sacrificio de que podría hablarse en todo caso sería la renuncia al amor de Antía en V 9, 13, pero el autor ni siquiera la ve bajo tal perspectiva. [óyvìv], añadido por Dalmeyda, expresaría esto de algún modo, pero nos parece totalmente superfluo: es la típica conjetura a partir de la reinterpretación (errónea además) de un texto.

16 Nótese que aquí Hipótoo a la vez se lamenta de su propio infortunio. En III 10, 3 es toda la banda de Hipótoo la que consuela al héroe. 
de decisión del héroe se revela incluso en el hecho de que es él el que, por inversión, estimula a Hipótoo a buscar a Antía (III 3, 5 s.); Abrócomes tiene iniciativas propias con frecuencia (así, para viajar en varias ocasiones: II, 12, 2, etc.) y la vieja función dinámica del estímulo del «amigo» se ve lógicamente muy reducida, lo que no es obstáculo para que continúe viva su función de auxiliar. En cuanto a la colaboración, aparte de aquella de tipo más general que se supone en el hecho mismo de la compañía, apenas si se encuentra sino en la forma de ciertas promesas, que, además, son mutuas, en el encuentro inicial ( $\sigma \cup v \varepsilon \rho \gamma \eta ́ \sigma \varepsilon ı v$, $\sigma \cup \lambda \lambda \eta ́ \psi \varepsilon \varepsilon \sigma \theta \alpha \mathrm{l}$ : II 14). Respecto al motivo del emparejamiento, se produce con carácter activo, es decir por iniciativa del «amigo», en la propuesta hecha en ese mismo encuentro inicial, así como luego en V 9, 2, en su deseo de compartir con el héroe sus riquezas ${ }^{17}$; pero hemos de notar que existe igualmente, como emparejamiento de nuevo cuño y que afecta a la propia estructura del relato, en el paralelismo relativo de la historia erótica (III 2, 1 ss.) de Hipótoo respecto a la propia de Quéreas, en el también relativo de la lamentación en III 3, 2 e incluso en la yuxtaposición de la pareja Hipótoo-Clístenes, que al final de la narración aparece como más intencionadamente complementaria de la de Abrócomes-Antía que aquella representada por el matrimonio de Policarmo en el desenlace de Caritón ${ }^{18}$. Por lo que se refiere al motivo del elogio, al haber simplificado extremadamente Jenofonte el final de su historia, no ha lugar ni a discursos ni a elogios del «amigo», frente a lo que sucedía en Caritón; antes bien se da una inversión del motivo al ser Hipótoo el que en su ya citado primer encuentro (II 14) elogia al héroe, en un episodio que, como vemos, desde diversas perspectivas posee una gran relevancia en la obra y en el plan narrativo de Jenofonte. Algo semejante ocurre con recompensa, afectada no ya por la supresión de un final equiparable al de Caritón, sino por el hecho de que la situación de Hipótoo no es comparable en absoluto a la de Policarmo. Tal como ya se ha recordado, es Hipótoo el que desea compartir su bienestar con Abrócomes, y asímismo su unión erótica con Clístenes excluye cualquier recompensa matrimonial.

En resumen, en el ámbito de los motivos no hay duda de que cuantitativamente el «amigo» se ha empobrecido, si lo comparamos con el Policarmo de Caritón, pero que Jenofonte ha profundizado y enriquecido unos pocos de ellos. Bastantes de los motivos más positivos, reiterados y hasta mecánicos de aquel antecesor se han visto anulados, reducidos o incluso invertidos. Pero a la vez se ha creado para el «amigo» una red más compleja de relaciones, diversificándose sobre todo su compañía (el héroe en contrapartida es más resuelto), repartida entre el héroe y la heroína. Y se ha dignificado narrativamente su papel, dotándolo de una autonomía muy notable.

El capítulo de los atributos nos informa también de cambios profundos en la personalidad del «amigo». Los términos de la familia lingüística de pí̀oఢ son

17 Una inversión (que no pasa además del puro deseo) del motivo de la recompensa económica en Caritón.

18 Recuérdese que la boda del «amigo» en Caritón pertenecía al capítulo de las recompensas. Aquí en cambio estamos ante una acción de la propia iniciativa erótica del «amigo». 
usados parcamente por Jenofonte en el ámbito de la amistad (más en el erótico, que no nos interesa aquí) y, de manera concreta, de la relación entre Hipótoo

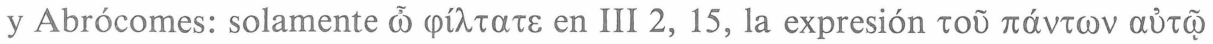

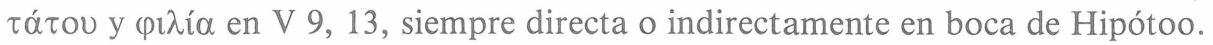

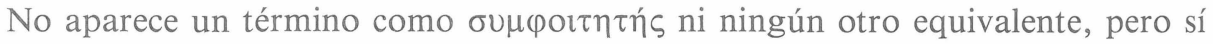

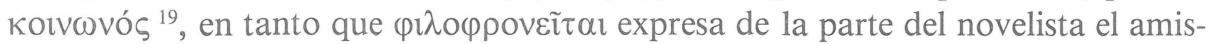
toso trato de Hipótoo a Abrócomes en su primer encuentro (II 14, 2), como espontáneo arranque de una incipiente amistad que supla la antigua fraternidad juvenil que encontrábamos en Caritón.

En lo tocante a rasgos de carácter o conducta, Hipótoo reparte su afecto y su lealtad entre Abrócomes y Antía (sobre su papel como «agresor» se hablará después) y también muestra su compasión hacia ésta ( $V 9,11)$. Una vez que ha «reconocido» a la joven por segunda vez $(\mathrm{V} 9,13)^{20}$ y tras la renuncia a sus pretensiones eróticas, se comporta en adelante con ella como «amigo», exactamente igual que antes con Abrócomes, en función de auxiliar en la búsqueda del esposo. Otras cualidades de Hipótoo proceden de su carácter decidido, pero a la vez sagaz y precavido ${ }^{21}$. Y en cuanto a las notas sociales, no hay duda alguna: según su propia información (III 2), su status de malhechor ha sucedido por imperativo de la necesidad ${ }^{22}$ a otro de nivel social alto y de prosperidad, al cual retornará posteriormente, con lo que será recuperado para el orden establecido, tal como éste se refleja en la novela.

Hipótoo, aunque leal, no puede demostrar en ningún momento su posible abnegación, excepto en su renuncia erótica citada. Es pragmático, pero sobre todo en una dirección muy distinta de la de Policarmo, al buscar de continuo la riqueza, aun a costa de casarse con una vieja $(\mathrm{V} 9,1)$; no recurre a engaños, ni beneficiosos ni de otro tipo, pero muestra su prudencia y discreción, por ejemplo en su actitud respecto a Antía en V 9, 5 ss.

Hipótoo es centro del relato en diversas etapas a lo largo de los libros II-V, y por supuesto en su autobiografía de III 2, a la que nos referiremos después y en la que es el héroe erótico de una historia digresiva y autónoma. Es también narrador en otras varias ocasiones: en V 9, 9 y 9, 13, con relatos en estilo indirec-

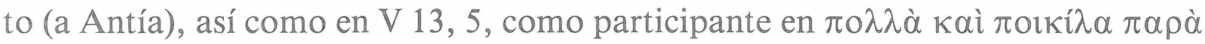
$\pi \alpha ́ v \tau \omega v \tau$ ì $\delta i \eta \gamma \eta ́ \mu \alpha \tau \alpha$. Y es personaje-enlace entre Antía y Perilao en II 11, 11, y auxiliar informativo en III 3, 4 s. (de Abrócomes acerca de Antía).

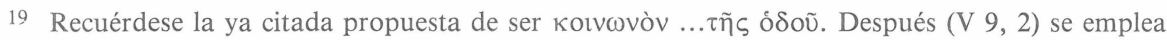

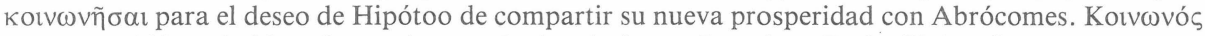
se usa también referido a los antiguos y leales sirvientes Leucón y Rode (V 15, 4).

20 Podemos llamar primer «reconocimiento» de Antía por Hipótoo al pasaje previo (V 9, 5) en que el «amigo» reconoce en la joven a su antigua cautiva, pero no a la esposa de Abrócomes, como es natural.

21 Recuérdense sus huídas cuando la banda es por dos veces atrapada (II 13, 4 - añádase el detalle del caballo oculto: II 14, 5- y V 3, 3).

22 Es una hipótesis por lo menos indemostrable la de Dalmeyda (p. XXIII n. 1 de su edición) sobre una supuesta justificación del cambio de conducta moral de Hipótoo por «sa passion deçue», naturalmente en la redacción primitiva y completa de la obra. 
Hipótoo, si bien no es descrito físicamente (al igual que Policarmo), sí nos es presentado como un individuo que ya ha dejado atrás la edad juvenil (cf. el nostálgico vÉoৎ ڤ̋v de III 2, 2). De él se nos da una autobiografía, en que entran en cuenta sus orígenes y la historia desdichada de unos antiguos amores que alteraron su vida. Este pasaje autobiográfico, que nos distancia grandemente del tipo representado por Policarmo y de su vacío biográfico, tiene muy diversos y notables aspectos y requeriría un análisis más detallado. Por lo pronto, como relato, tiene una doble función: de un lado y a primera vista es una mera digresión, al no ser dinámico respecto a la acción principal, pero es claro que sirve para enmarcar al «amigo» en una perspectiva ennoblecedora, por contraste con su actual degradación como bandido, con lo que resulta nivelado socialmente con el joven protagonista; de otro lado, dota a Hipótoo de unos antecedentes que también lo nivelan con Abrócomes (amores y peripecias desdichadas) y luego con el viejo pescador Egialeo, lo que nos confirma la afición de Jenofonte por los paralelos y los juegos de simetrías. Pero, además, la historia erótica relatada, que será luego subrayada por la relación entre Hipótoo y Clístenes en el libro V y por la pasajera pasión de Hipótoo por Antía ${ }^{23}$, nos revela una vertiente bisexual de este «amigo» (con mayor peso de la cara homosexual, si se desea), que tiene a su vez dos consecuencias que nos parecen importantes: la una, llenar el vacío erótico que convertía en bastante antinatural la figura del «amigo» en Caritón; la otra, desvelar hasta cierto punto el ambiguo carácter de su actitud en el primer encuentro con Abrócomes ${ }^{24}$, aunque su comportamiento con el protagonista se resolverá después en una dirección asexuada, al modo de Caritón.

Jenofonte se atiene en cambio estrictamente al atributo de la singularidad, es decir la no pluralidad del personaje del «amigo», según el modelo legado por Caritón. Esta afirmación quizás pueda sorprender, ya que el pescado Egialeo representa al menos en apariencia un competidor de Hipótoo. Pero las diferencias entre ambos son radicales, si nos atenemos precisamente a las notas típicas del par Policarmo-Hipótoo. Para Egialeo no se utiliza jamás el grupo de términos

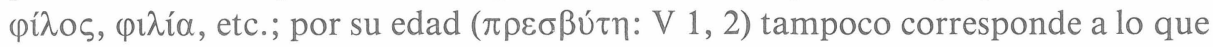
es típico del «amigo», incluso en el caso del adulto Hipótoo ${ }^{25}$, sino al tradicional anciano hospitalario al estilo de la Hécale calimaquea; un viejo, pues, que puede llamar $\tau \dot{\varepsilon} \kappa v o v$ a Abrócomes $(\mathrm{V} 1,4){ }^{26}$, que lo trata paternalmente ( $\pi \alpha \tilde{i} \delta \alpha$

$23 \mathrm{~V}$ 9, 11. El autor parece olvidar de inmediato esta cuestión, tocada sólo fugazmente. Pero merece la pena notar de paso que la propia Antía en su catálogo de sus agresores eróticos de V 14, 2 no mencionará a Hipótoo (ni al amable «rival» Anfínomo), lo cual dice mucho en favor de su discreción, ya que se trata de un relato recapitulador hecho a su esposo.

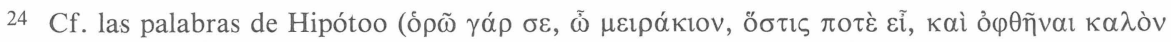

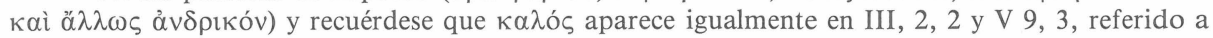
los jovencitos Hiperantes y Clístenes. A esta vertiente erótica de Hipótoo deben vincularse también sus manifestaciones sentimentales: así en III 1, 4; 2, 4 y 3, 2 s.

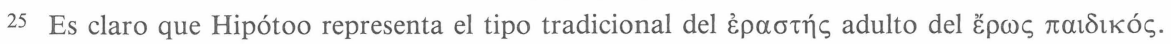
Jenofonte se aparta claramente de Caritón en este punto.

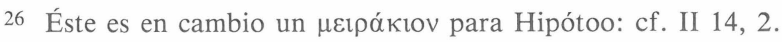




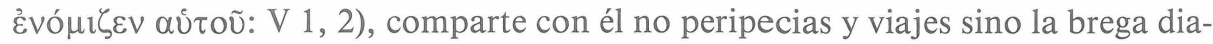
ria de su oficio y es calificado simplemente como $\xi \dot{\varepsilon} v o v(\mathrm{~V} 10,3)^{27}$.

Por lo que se refiere a la relación jerárquica, dada la radical autonomía del personaje de Hipótoo apenas si puede hablarse estrictamente de subordinación o al menos no de un modo comparable a la que se daba en Policarmo respecto a Quéreas. Su carácter de auxiliar (ayuda en la búsqueda) está repartido entre los dos protagonistas, pero con mayor peso en favor de Antía. Pero, por otro lado, al ser Hipótoo jefe de una banda en la que de modo un tanto atípico aparece por un tiempo integrado Abrócomes como extraño huésped, Jenofonte ha creado una vinculación nueva entre el «amigo» y el héroe.

Por lo demás el «amigo» no parece sufrir eclipsamientos, al menos dignos de nota ${ }^{28}$. Y nos queda por examinar un par de atributos que responde a uno de los aspectos más novedosos del tratamiento del «amigo» en Jenofonte de Efeso. En el caso de Policarmo veíamos cómo éste mantenía una especie de neutralidad respecto a Calírroe, o quizás sería mejor decir indiferencia, desde el momento en que era exclusiva su dedicación al héroe masculino. Incluso en alguna etapa crítica de sus comunes avatares llega a abominar de Calírroe culpándola de sus desgracias (IV, 2, 7) y en otra estimula al héroe a un nuevo amor (VIII, 1, 6), convencido de que el primero, por Calírroe, está ya definitivamente frustrado. Pero es éste el límite de la relación negativa entre Policarmo y Calírroe. En cambio Hipótoo, aparte de desarrollar intensamente su relación positiva con Antía, convirtiéndose en eficaz auxiliar de ésta, aparece también como «agresor» ${ }^{29} \mathrm{y}$ momentáneamente como enamorado, y por tanto como «rival» de Abrócomes ${ }^{30}$. El atributo de «agresor» tiene unas connotaciones argumentales sin embargo que no son desdeñables. Ha de recordarse que la agresión de la banda de Hipótoo en II, 11, 11 libera a Antía de los comerciantes de Cilicia y termina poniéndola en manos del «rival» Perilao y la de IV, 3, 5 representa su liberación del bárbaro Psamis ${ }^{31}$, con lo cual la agresión repetida se transforma decididamente en una suerte de auxilio. Es más, el propio castigo de IV 6, 3 conducirá a la intervención del benévolo Anfínomo, «rival» el más amable posible aunque de rango muy secundario. En cuanto al atributo mismo de «rival» como enamorado de Antía, $\tan$ fugazmente vivido en la novela $(\mathrm{V} 9,11 \mathrm{~s}$.), sirve de pretexto en realidad para

27 Todo lo cual no significa que, en su función de auxiliar, Egialeo no participe de algunos motivos y atributos del «amigo». Así, consuela a Abrócomes (V 2, 1), es centro y narrador, etc. Por lo demás, Egialeo con la nota macabra de su extremada lealtad erótica conecta con el tema, reiterado en la novela, de la fidelidad hasta la muerte.

28 Lo que representa una novedad dentro de la técnica narrativa de Jenofonte. Éste ha tenido buen cuidado incluso de justificar, por ejemplo, la ausencia de Hipótoo en el momento en que Antía padece el acoso erótico de Anquíalo en IV 5, 5.

29 Recuérdese el doble cautiverio, el sacrificio de II 11-13 y el cruel castigo de IV 6, 3.

30 Por tal se entiende simplemente el enamorado de la misma mujer (en este caso que el héroe), sin atender a las circunstancias, por ejemplo al hecho de que Hipótoo ignore todavía en ese momento la relación entre Antía y Abrócomes.

31 Como en V 9, 9 la compra de Antía por Hipótoo supone también su liberación del proxeneta. Cabría hablar por tanto de un nuevo motivo en el «amigo»: el de la liberación de la protagonista femenina. 
el inmediato «reconocimiento» de la joven, y la misma rapidez del tratamiento parece indicarnos que el episodio es muy secundario para el novelista en su aspecto erótico, de modo que apenas llega a aportar al «amigo» una faceta nueva de verdadero relieve. Tras el «reconocimiento» de Antía como esposa de Abrócomes el incidente cesa y la pasión de Hipótoo, inicialmente presentada con la fogosidad típica del auténtico «rival», se desvanece sin mayores consecuencias.

Si hacemos, pues, un balance acerca del «amigo» en Jenofonte de Éfeso, es claro por lo pronto que el personaje escapa a la muy acusada funcionalidad y al rígido esquematismo del Policarno de Caritón. Es un tipo mucho más rico, y en algunos aspectos bastante novedoso frente a su modelo. Son de destacar sobre todo su más subrayada autonomía, el conocimiento biográfico de que dispone el lector sobre él, su doble vinculación a los protagonistas y su múltiple función como «amigo» (y auxiliar consecuentemente), «agresor», «rival»y héroe erótico de una historia propia. Por otra parte, si ciertas facetas le proporcionan al «amigo» una personalidad más acusada, las funciones de «agresor» y «rival», aunque marginales y muy instrumentales, permiten la introducción de nuevas y finas complicaciones en la trama novelesca, como ocurre por ejemplo con la escena de la compra de Antía al proxeneta y el doble «reconocimiento» siguiente: un primer «reconocimiento» al nivel de antigua víctima y «agresor», un segundo al nivel de «rival»y «amigo» del esposo ${ }^{32}$. Y en cuanto al papel de héroe erótico, que añade un elemento de humanización al personaje un tanto deshumanizado que representara Policarmo, crea, como hemos señalado, una sutil ambigüedad en la vinculación del «amigo» con Abrócomes, que se acrecienta por la edad asignada

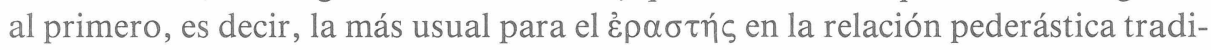
cional. La necesidad de resolver juiciosamente esta ambigüedad quizás haya forzado un tanto al autor a disponer de una criatura tan borrosa como el adolescente Clístenes, que cabría interpretar como una mera encarnación de las posibilidades del propio Abrócomes en su hipotética relación erótica con Hipótoo ${ }^{33}$. Sin embargo, tampoco hay que olvidar que la vida introducida por Jenofonte en el personaje del «amigo» conlleva a su vez aspectos de degradación moral, como ocurre sobre todo con su profesión (temporal por supuesto) de malhechor, y de un pragmatismo muy marcado, tal como vemos en sus ambiciones pecuniarias y en su interesado casamiento en Sicilia, aunque es justo reconocer que el autor impone también una cierta degradación a sus propios héroes, alejándose del idealismo de Caritón: Abrócomes acompaña sin escrúpulo alguno a la banda de $\mathrm{Hi}$ pótoo y trabaja en oficios serviles; Antía, si bien involuntariamente, termina, des-

32 Por lo demás, la repentina pasión de Hipótoo por Antía cumple una doble función: la de presentar a aquél como «rival», ya notada, y la del auxilio tras el «reconocimiento», ya que desde ese momento Hipótoo secundará a la heroína en su búsqueda del esposo.

33 No sólo ambos (como también Hiperantes) son $\kappa \alpha \lambda$ oí, como ya señalamos, sino que también

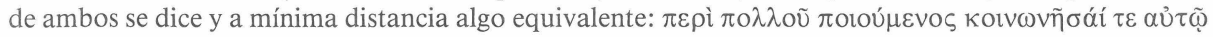

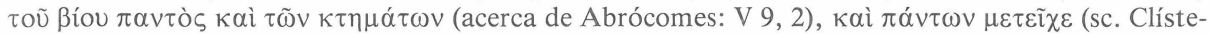

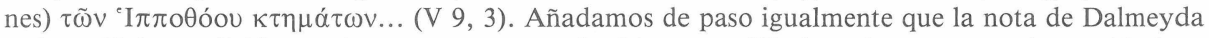
en la p. 68 de su edición contiene un craso error: los bienes que Hipótoo desea compartir con Abrócomes son los procedentes de su reciente matrimonio; recuérdese que poco antes $(\mathrm{V} 9,1)$ Hipótoo estaba

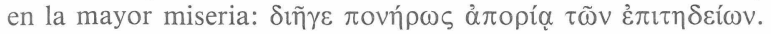


pués de múltiples avatares, en una casa de lenocinio. Este último aspecto es muy importante, ya que significa en la novela una pérdida en la sublimidad a que tanto propende el género y no deja de proporcionar una atmósfera explicativa de la inmoralidad de que a veces ha sido acusado Hipótoo. Como ha indicado acertadamente el propio Gärtner (loc. cit.), Abrócomes no se escandaliza de las actividades delictivas de su «amigo» ni tampoco ningún otro personaje, ni menos nadie muestra su sorpresa por el hecho de que éste sea ayer un honrado joven, hoy un despiadado bandolero y mañana de nuevo un respetable burgués, como si tal metamorfosis fuese lo más natural del mundo. El «amigo», pues, sufre en Jenofonte una degradación moral y social en consonancia con la que a nivel amplio se da en la novela, reflejo agudo seguramente de la del mundo en que ésta fue creada.

En Dafnis y Cloe de Longo el personaje del «amigo» se diluye de modo muy notable. De un lado, un «rival» y a la vez auxiliar eventual como Dorcón está limitado al ámbito del primer libro y en él predomina con mucho el papel de «rival». Su relación con el héroe masculino, Dafnis, es indirecta, en el sentido de que los enfrenta y al final los une el común amor a la protagonista. De otro, el anciano Filetas, en el libro II, es básicamente un auxiliar informativo (sobre el amor) y su edad y actitud lo aproximan mucho más en todo caso al Egialeo de Jenofonte que a Policarmo o a Hipótoo. Y todavía el sirviente Éudromo o el joven señorito Ástilo están bien alejados del tipo del «amigo» tradicional. Ástilo, auxiliar y finalmente hermano de Dafnis ${ }^{34}$, tiene una intervención muy fugaz en la obra, exactamente como Éudromo. Éste último podría ser a lo sumo el más cercano al «amigo». Incluso por dos veces se alude (IV 9, 3 y 18,1$)$ a su afecto

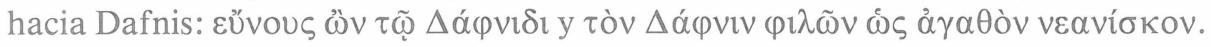
Pero su nivel de mero sirviente y su escaso relieve lo excluyen de esta consideración.

Podríamos decir que Longo ha repartido vagamente las funciones del «amigo» entre una serie de personajes, que a su vez han sido distribuidos estratégicamente por la novela, y todos ellos capaces de proporcionar diversos auxilios, aunque en algún caso también con notas negativas de «rival» o de «agresor», como ocurre con Dorcón. El sacrificio mismo de éste no es en absoluto en favor del joven protagonista, sino de su propia vacada, y por tanto un acto interesado. Dorcón es también capaz de engaño (I 20), pero en su papel de «rival» y a costa de los dos protagonistas. Y sus recompensas (el beso de Cloe y su entierro en I 30, 1 y 31,3$)$ le vienen de su función de bienhechor, es decir de un auxilio que tiene como origen su amor hacia Cloe y no la estricta amistad.

De la comparación entre Longo, de una parte, y Caritón y Jenofonte, de otra, es fácil deducir que el personaje del «amigo», definido primariamente como asiduo acompañante, parece incompatible con la historia sedentaria narrada por Lon-

34 Parentesco y amistad parecen relativamente incompatibles en la novela griega, si exceptuamos un caso como el de Clinias en la de Aquiles Tacio. 
go y requiere en cambio el tipo de héroe viajero, amenazado por la soledad y los riesgos. En Longo no existe sino un viaje espiritual y una suma de pequeños avatares. El «amigo», pues, parece haber sido una figura esencialmente superflua. Los héroes de Longo sufren y gozan juntos de modo prácticamente continuo y un tercer acompañante, si se nos permite decirlo así, habría resultado una «carabina» desairada y la ruina de tan hermosa historia.

\section{IV}

Por contraste con la práctica de Longo, la novela de Aquiles Tacio nos ofrece un amplio campo de observación para nuestro tema. Por lo que se refiere a él lleva a cabo una innovación fundamental, aunque tenga algunos antecedentes ya en Caritón y Jenofonte: la de arrancar al héroe de su soledad para hacerle vivir sus peripecias inmerso casi continuamente en un grupo. Tanto en la extensa primera parte, con los sucesos de Tiro, como en la continuación viajera, Clitofonte está rodeado de una solidaria y afectuosa compañía. Es un grupo el que marcha errante, con una técnica que reencontraremos por momentos en Heliodoro. Los dos protagonistas sufren las tradicionales separaciones ${ }^{35}$ desde luego, pero es corto el plazo en que no se saben realmente cercanos el uno al otro, aunque impedidos de reunirse por diversos obstáculos. Hay, pues, en Aquiles Tacio una tendencia muy «social» o gregaria, que influye decisivamente en la figura del «amigo». Por lo pronto éste pierde uno de sus atributos más negativos, la singularidad, puesto que a todas luces en esta novela no sólo hay dos jóvenes «amigos», Clinias y Menelao, sino que ambos tienen tanto en común que parecen hasta cierto punto funcionalmente un mutuo reflejo, sin que ello impida la existencia de diferencias, sobre las que habrá que insistir. Incluso por un tiempo un tercer individuo, Quéreas, convertido eventualmente en «amigo», acompañará al grupo, aunque pronto mostrará su verdadera faz de «rival» y «agresor» ${ }^{36}$. Claro es que en parte de las andanzas del grupo los «amigos» propiamente dichos se relevan, demostrando que la singularidad de la tradición no ha perdido su eficacia. Clinias es el acompañante habitual hasta el episodio del naufragio (III 5) y vuelve a serlo desde su reaparición en V 8, $2 \mathrm{~s}$. hasta el final del relato; Menelao, más brevemente, lo es desde el encuentro en el barco (II 33, 1), con una corta separación tras el naufragio, hasta V 15, 1. La doble compañía, con ambos «amigos» presentes, se reduce a dos breves etapas: en el barco hasta el naufragio, cuando Menelao no responde aún al estatuto de «amigo», y, en Alejandría, tras la reaparición de Clinias. Incluso podemos decir que esta reaparición conlleva el que Menelao sea «expulsado» de la narración, quedando patente también que la doble compañía era

35 Desde III 12, 2 hasta 17, 7, y desde V 7 en realidad hasta 17, 3, aunque el autor aplace el encuentro definitivo hasta el final de VII. Sin embargo, Aquiles Tacio huye del viaje prolongado y continuo, sustituyéndolo parcialmente por dilatadas estancias (en Tiro y luego en Éfeso), en que las separaciones que cabría llamar «geograficas» de los amantes son reemplazadas por separaciones más limitadas pero a la vez más dramáticas. El contraste en especial con Jenofonte de Éfeso es muy elocuente.

36 Nótese que, a diferencia del status social alto de los auténticos «amigos», Quéreas es de baja extracción: cf. IV 18, 1 s. sobre su origen humilde y sus oficios de pescador y mercenario. 
funcionalmente innecesaria. En cambio, la figura del sagaz esclavo Sátiro sí supone una compañía no sólo mucho más estable sino también bastante eficaz en sus iniciativas y sus artes y compatible a la vez con la presencia de ambos o de uno u otro «amigo», lo que se explica por el hecho de que los papeles del siervo y del «amigo» estaban en la tradición del género (como sin duda en la vida real) bien delimitados.

En lo esencial motivos y atributos se corresponden con los ya estudiados en Caritón y Jenofonte y, en beneficio del lector, podemos dejar de lado algunos detalles, reduciendo el análisis a aquellos aspectos más notables o que requieren ciertos comentarios, así como a las diferencias relevantes entre uno y otro personaje.

El papel de Menelao, aunque más breve que el de Clinias, tiene sin embargo gran peso sobre todo en los libros III-V. Aparece con rasgos muy positivos, como un joven rico, varias veces objeto de elogio (vd. después), cortés, prudente, sagaz y sentimental. Se nos da de él una breve autobiografía (II 33, 2 ss., y III 19), en que se incluye un relato pederástico de final desdichado y en la forma de narración autónoma (Menelao por tanto como narrador y centro de relato) ${ }^{37}$. Su compañía oscila entre fortuita (encuentro en el barco en II) y en parte al menos voluntaria ( en los sucesos de Egipto), pero es contrarrestada luego por sus renuncias a continuar de acompañante en $\mathrm{V} 6,1$ y definitivamente en $\mathrm{V} 15,{ }^{38}$. Actúa de teórico del amor pederástico (II 35 ss.), de modo coherente con su relato autobiográfico, y con una personalidad bastante autónoma en la trama novelesca. Entre sus motivos de más realce están, además de la ya citada compañía y de una colaboración sólo como auxilio general (como ocurre con Clinias), el impedimento de suicidio (con Sátiro: III 17) ${ }^{39}$, el consuelo (V 8, 1) ${ }^{40}$, el estímulo (IV 8, 4), el engaño beneficioso (III 18 ss. y IV 6, 3), el sacrificio (III 22, 1) ${ }^{41}$ y el elogio (de parte del autor: V 15,1$)^{42}$, todos los cuales suman un buen número, si bien el novelista ha sido extremadamente parco en su empleo, con la justificación muy razonable de que ha debido repartirlos entre dos «amigos».

En cuanto a sus atributos (ya se citaron centro y narrador), es calificado de «amigo» por supuesto y su origen es acomodado (su presentación en II 33 es sig-

37 Es centro también de algún otro episodio, por ej. III 17 ss., pero en combinación con el carácter de narrador igualmente.

38 Aquiles Tacio, tan cuidadoso en los detalles, justifica de modo explícito la primera renuncia, de carácter sólo temporal, e implícitamente la segunda, ya definitiva: Menelao permanecerá en Egipto, que es su tierra y, en fin de cuentas, el destino de su propio viaje.

39 En V 7, 5, cuando hay un impedimento no individualizado, no está presente Menelao (cf. su primera renuncia a la compañía en V 6,1). No se trata por tanto de un eclipsamiento. Recuérdese, por lo demás, que ya en Jenofonte de Éfeso (III 10,3) había un motivo en equipo, el del consuelo.

40 En IV 10, 1 consuelan a Clitofonte «los que estaban con Menelao».

41 En este pasaje son muy significativas las palabras, de tono sentencioso, del propio Menelao:

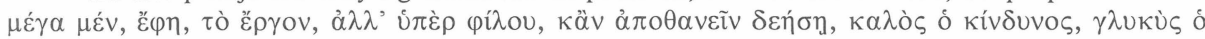
$\theta \dot{\alpha} v \alpha \tau$ os.

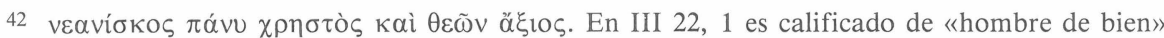

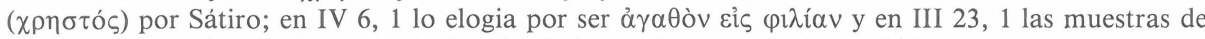
agradecimiento de Clitofonte equivalen de algún modo a un elogio también. 
nificativa); su actitud es digna y leal a la par que sagaz y prudente, y no carece de sentido del humor ${ }^{43}$. Su vacío descriptivo se contrarresta con sus cualidades morales y sus datos biográficos y eróticos, suficientes en el género en que nos movemos. Sufre algunos indiscutibles eclipsamientos, como ocurre al comienzo de los libros IV y V o en el pasaje (V 12) en que Sátiro y Clinias animan a Clitofonte a corresponder al amor de Mélite, una escena en que Menelao está indudablemente presente pero en que no se le menciona. Su autonomía, muy marcada, impide que pueda hablarse realmente de subordinación más allá de la que supone el auxilio típico del «amigo».

La relación de Menelao con Leucipa parece partir de la neutralidad que hallábamos en Caritón, pero con determinadas concesiones a los cambios implantados en Jenofonte de Éfeso. Así, en III 22, 1 s., tras aludirse al riesgo que se corre «por un amigo», Sátiro subrayará que Menelao con su conducta obtendrá la gra-

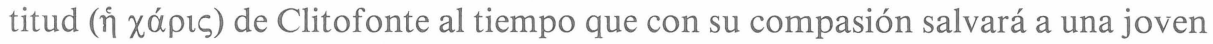

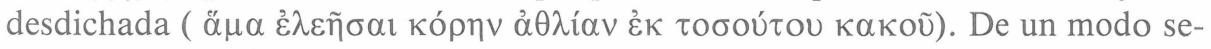

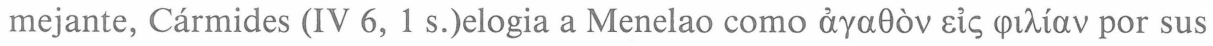
actos en favor del héroe, para añadir luego que la propia Leucipa le debe la vida. Y la salvación de Leucipa en la escena del falso sacrificio (recuérdese ya en el caso de Hipótoo el nuevo atributo de libertador de la heroína) e igualmente su hábil juego salvador en el episodio de Cármides hemos de entenderlos a la par como un servicio a Clitofonte y como un acto de generosidad, pero de ningún modo como indicio de otra relación más positiva con la joven heroína.

En suma, por más que Menelao (como Clinias) forme parte del grupo y acompañe a la pareja protagonista y actúe en favor de Leucipa, esta vinculación con la heroína esta subordinada a la que se da entre el héroe y el «amigo» y es por tanto secundaria. Por otro lado, es importante recordar que su papel de intermediario erótico, en el caso de Menelao (cf. $\tau \tilde{\eta} \varsigma ~ \delta ı \alpha$ kovías en IV 6, 2), en favor del $\sigma \tau \rho \alpha \tau \eta \gamma o ́ \varsigma$ Cármides y a costa de Leucipa es sólo una añagaza episódica, por lo que el autor no hay duda de que nos lo presenta como una actuación más en pro de los protagonistas. Hay, pues, una traición sólo simulada y benéfica, tal como hay una profesión de malhechor también sólo simulada. Esta capacidad de simulación es un elemento nuevo en la sicología del «amigo», pero, paradójicamente, en línea con su lealtad. Si su emparejamiento con el héroe, por otra parte, como ocurrirá igualmente con Clinias, es apenas relevante y simplemente derivada de la compañía, es en cambio notable su actuación codo a codo con el siervo Sátiro e incluso en cierto modo en dependencia de éste, lo que también supone una nota nueva, sobre todo en el pasaje del falso sacrificio: la tradición del siervo tramposo se impone en situaciones así. Sátiro en tales momentos es la figura decisiva y Menelao meramente su auxiliar.

Respecto a Clinias, si descontamos la etapa de su desaparición de escena a raíz del naufragio (desde III 5 hasta V 8), prácticamente está presente todo el res-

43 Cf. su capacidad de simulación en III 19 y IV 6, su prudencia supersticiosa en V 4 y su dignidad combinada con sagacidad en la respuesta a Cármides en IV 6, 3. El humor se manifiesta en su teatral farsa de III 18, 2 s., a costa precisamente del ingenuo protagonista. 
to de la novela y, aunque sufre eclipsamientos muy señalados, su papel es complejo y responde aun mejor y más cabalmente que Menelao al tipo que ya conocemos. Por lo pronto, es el «amigo de siempre», además de pariente, no renuncia de modo voluntario a la compañía, a diferencia de Menelao, y se supone que su papel de «amigo» durará lo mismo que su propia vida en la vecindad de Clitofonte.

Bastantes de sus motivos y atributos concuerdan por supuesto con los de Menelao, pero las discordancias son evidentes. Es también un joven acomodado, pragmático y reflexivo y a la vez sentimental. Su pragmatismo se exterioriza en el de-

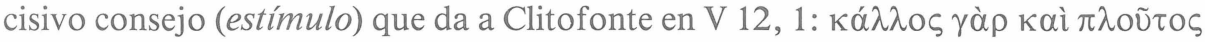

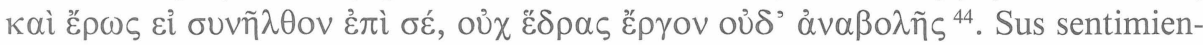
tos brotan de modo espontáneo: así en el final patético de sus amores en el libro I $(13 \text { s. })^{45}$, en su alborozado reencuentro con Clitofonte en V 8, 2 s., en su llanto, sus lamentaciones o su alegría de VII 9, 2 y 12, 2; 14, 6 y 15,3, y su solución a los problemas planteados en II 27, 1, y su estímulo a reflexionar y hacer planes en VII 11, 3 revelan en él una madura personalidad. El engaño a que somete a su propia familia para poder seguir a Clitofonte (V 10,1 ss.) no puede menos de recordarnos una acción comparable de Policarmo en Caritón y subraya su propia discreción. Es centro de un episodio biográfico autónomo (sus amores desdichados en I), también de tema pederástico, y actúa de nuevo como centro y como narrador en V 9 s. de sus propios avatares tras el naufragio y en VII 9, durante el juicio. No sólo es acompañante del héroe con toda la constancia posible, sino que su compañía es manifiestamente voluntaria (cf. II 27, 2), después del naufragio procede a su búsqueda por su propia iniciativa $(\mathrm{V} 10,7)$ y aún acompañará a la pareja Mélite-Clitofonte con la promesa de sólo regresar a su casa si ve que a éste último le va todo bien ${ }^{46}$. Hay, pues, un empeño en velar por el joven héroe, revelado ya en su tutela y magisterio erótico en el libro I y según su reconoci-

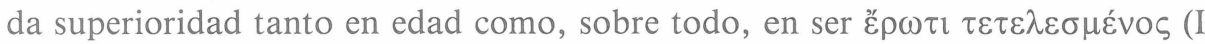
$7,1)$. Procede también a un impedimento de suicidio, que hemos de calificar de

44 En este episodio el autor ha repartido hábilmente los papeles: eclipsa a Menelao, el «amigo» menos familiar y menos apropiado para este delicado estímulo; convierte a Clinias en el único conse-

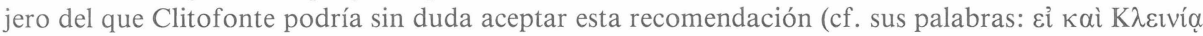

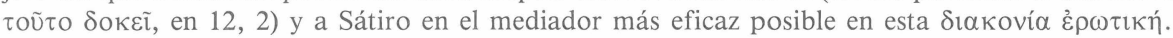

45 El paralelismo en este punto, como en otros, con Menelao es evidente incluso en el común sentimiento de culpa por la muerte del jovencito amado: cf. I 14, 1 ss., y II 34, 5 s. Y no es sorprendente que el propio autor subraye en II 34, 7 las semejanza entre las desdichas de ambos. Pero a la vez un sentimiento equiparable lo encontramos en Clitofonte, que se culpa a sí mismo por la supuesta muerte de Clinias (III 23, 3). Por otra parte, las historias desdichadas de ambos «amigos» son las que los ponen en situación de disponibilidad por igual para integrarse en el grupo viajero y asociarse a la compañía de los protagonistas. Sólo en el caso de Clinias se sabrá más tarde que, a pesar de ser huérfano, aún tiene una familia a la que dar cuenta de su ausencia (cf. II 27, 2 y V 10, 1 ss.).

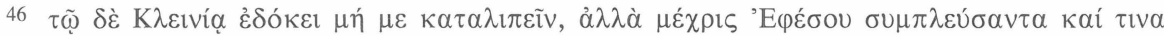

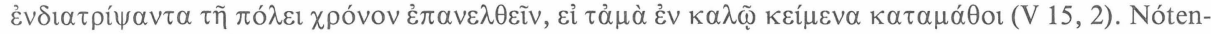
se además tres hechos: que la compañía de Clinias, según las perspectivas del momento, es aparentemente ociosa, dado que no amenazan peligros al héroe en este viaje (esto se demostrará falso después), y por tanto el empeño en acompañarlo tiene significado por sí mismo; que en realidad Clinias, según deja bien establecido el texto, acompaña a Clitofonte, no a la pareja (neutralidad o indiferencia frente a Mélite); y, por último, que la frase citada está contrapuesta a la renuncia a la compañía por parte de Menelao. 
novedoso desde el punto de vista de la técnica narrativa, tanto cuando censura el plan vengativo de Clitofonte en VII 6, $4^{47}$, como luego durante el juicio, en que el impedimento adopta la forma de una defensa judicial (VII 9), en un episodio doblemente interesante porque a la vez se produce en él una cierta inversión (por ejemplo, respecto a la práctica de Caritón): es el «amigo» el que reprueba y rechaza una decisión del héroe, en vez de ser él el motor del estímulo, tal como lo es de hecho, por citar un caso, en su pragmático consejo ya aludido. Clinias representa modalidades de auxilio muy concretas en momentos determinados: así cuando trata de contener el furor de Sóstrato contra Clitofonte (VII 14, 4) o cuando intenta protegerlo de la violencia de los guardias (VII 16, 1); da consuelo no sólo al héroe (VII 6, 1 s.) sino a algún otro personaje (a Sóstrato en VII 14, 5), se muestra capaz de un abnegado sacrificio en VI 14, 1, emparejado con el siervo Sátiro ${ }^{48}$. Del testimonio o declaración en favor del héroe en el juicio hemos hablado ya, así como del engaño. En cuanto a ser objeto de elogio y recompensa, encontramos ciertos aspectos francamente llamativos. Por lo pronto, la recompensa no ha lugar, un punto en el que Aquiles Tacio va mucho más allá que Jenofonte: no sólo Clinias (tampoco Menelao) no recibe compensación alguna por sus ayudas y desvelos, sino que en el abrupto final de la obra Clinias es eclipsado de modo radical. En la recapitulación en boca del propio Clitofonte (VIII 4, 5) sólo se nombra, y muy de pasada, a Menelao; no a Clinias ni a Sátiro. Y Clinias asímismo es desplazado en una escena de hospitalidad (VIII 7, 2). No hay, por tanto, un elogio al final de la novela, como ocurría en Caritón, ni una cumplida mención, como era el caso en Jenofonte. En cambio, las lamentaciones que su desaparición y supuesta pérdida hacen pronunciar en una ocasión a Clitofonte tienen un cariz elogioso que raya casi en lo erótico: en III 23, 3, donde el héroe

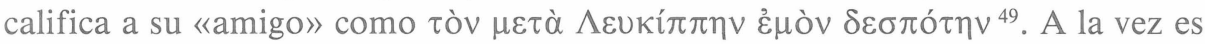
evidente que la relación entre Clinias y Clitofonte es mucho más familiar y afectuosa que la que se da entre Clitofonte y Menelao, y el autor ha cuidado de subrayarlo. La amistad entre los dos primeros es muy espontánea y abierta a naturales

47 De hecho, este impedimento fracasa, ya que Clitofonte llevará adelante su proyecto. Es el relato mismo el que dará un giro a la situación y solucionará el problema de esta indirecta tentativa de suicidio. En este mismo impedimento Clinias actúa a la par del siervo Sátiro: cf. VII 6, 6.

48 La pretensión del «amigo» aquí de sufrir idéntica prisión que Clitofonte recuerda de algún modo el común deseo de Policarmo y Quéreas de ser vendidos juntos en Caritón (III, 7, 3) y los sacrificios de Policarmo en ese cautiverio. Por otra parte, el emparejamiento de Clinias con Sátiro (entiéndase este motivo como una desviación del normal, que es respecto al héroe) llega en ése y en otros casos a grados muy notables: así, en la actuación de estímulo erótico de ambos en I, más teórico desde luego en Clinias, y comparables a las actuaciones emparejadas de Sátiro y Menelao en III. En el estímulo a un nuevo amor (V 11 s.) la acción de Sátiro y Clinias es claramente complementaria. Y en VI 15, 1 el autor curiosamente subordina (o eclipsa, si se prefiere) a Clinias respecto a Sátiro al hablar

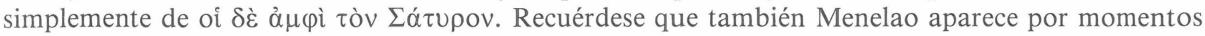
subordinado a Sátiro.

49 Recuérdese el empleo erótico corriente de $\delta \varepsilon \sigma \pi$ ó $\rceil\rceil \varsigma$ y $\delta \varepsilon ́ \sigma \pi$ orv $\alpha$. En Aquiles Tacio concretamente cf. II 4, 4 y 6, 1, con $\delta \varepsilon ́ \sigma \pi o ı v \alpha$ para Leucipa, y V 11, 6, con Clitofonte como $\delta \varepsilon \sigma \pi$ ó $\rceil \zeta \varsigma$ de Mélite. 
expansiones ${ }^{50}$. La amistad entre Menelao y Clitofonte es, aparte de transitoria, más respetuosa y formal ${ }^{51}$.

Sobre otros atributos de Clinias, dejados de lado centro y narrador y los demás ya citados, cabe decir que no existe un vacío biográfico ni erótico en absoluto, pero sí, como en el caso de Menelao, un vacío descriptivo, tal como es tradicional. Este «amigo» está subordinado a Clitofonte más claramente que Menelao, y, por lo que respecta a los eclipsamientos, sufre algunos dignos de nota: en I 15, tras el episodio de sus trágicos amores, cuando desaparece abruptamente del relato: luego en parte del libro V y hasta VI 14, una etapa en la que es Mélite con su recia personalidad la que ocupa el centro de la narración, incluso como auxiliar, tal como ocurre en el momento de la fuga de Clitofonte al final de V y comienzos del libro siguiente; y también en el ya aludido final de la novela. La funcionalidad del personaje del «amigo» se muestra de este modo incluso en el (aparentemente) muy cuidadoso Aquiles Tacio ${ }^{52}$.

Este autor, pues, una vez que ha desdoblado la figura del «amigo», ha distribuido sus papeles a lo largo de su amplio relato, atribuyendo los motivos y atributos a ambos personajes de una manera casi prácticamente semejante. Ha evitado sin embargo que ciertos motivos más tópicos como impedimento y consuelo se reiteren demasiado y ha trazado diferencias importantes también entre los dos «amigos», a la vez que los ha sometido igualmente a unas actuaciones y situaciones hasta cierto punto simétricas. Sus propias historias y sus desenlaces son bien paralelos; ambos tienen la disponibilidad que el género parece exigir, pero no hay duda de que los dos personajes llenan de modo también matizadamente diferente el papel del «amigo». Hay entre ambos un muy distinto grado de proximidad personal al héroe, justificable en gran parte por sus diversas biografías, de suerte que del uno (Menelao) se podrá incluso prescindir casi en medio del relato sin mayores problemas. La competencia posible entre los dos se resuelve así, hallándose un hábil equilibrio entre la variedad que el hecho de ser dos aportaba y el riesgo de duplicación de sus actos. El sacrificado es naturalmente aquél en que el grado de familiaridad era menor. Ambos, por otro lado, son homosexuales, como Hipótoo, pero en ambos se excluye la tentación de la «rivalidad» erótica con el héroe que Hipótoo, por fugazmente que sea, sí padece. Los dos, por ello, retornan a la neutralidad respecto de la heroína que impusiera el modelo de Caritón. Son «amigos» del héroe y sus relaciones con Leucipa son extremadamente parcas. En cuanto a la propia relación con el héroe, es la que se da entre Clitofonte y Clinias la que más de cerca bordea esa tenue atmósfera de ambigüedad que el «amigo» arrastra ya desde la tenaz fidelidad de Policarmo y las más osadas

50 Cf. las efusiones de I 7, 3 y V 8, 2 s., así como la citada abnegación de Clinias y sus llantos y alborozos.

51 En III 23, 1 la reacción de agradecimiento de Clitofonte es muy espectacular, pero no la que

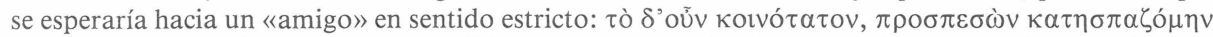

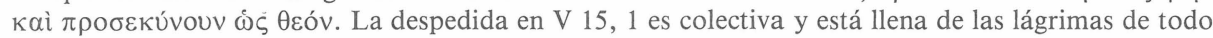
el grupo.

52 Clinias concretamente tendrá un papel muy activo en el libro VII, pero en cambio Sátiro está más oscurecido en ese mismo libro. 
expresiones de Hipótoo. La moralidad de la novela, en beneficio del amor conyugal, ha buscado ciertas vías de escape a esta tentación, con el resultado no obstante de ese punto oscuro en la figura del «amigo», que, adorando a los jovencitos, se muestra ejemplarmente casto al lado de esos héroes masculinos tan atractivos que la novela se recrea en presentar. El más precavido en este aspecto es sin duda Jenofonte, cuando crea al oscuro Clístenes, que cubrirá las necesidades sexuales de Hipótoo. Pero, en cambio, sin un Clístenes a su vera, los dos «amigos» de Clitofonte no poseen sino el recuerdo de sus tristes amores pasados. El novelista los ha dotado de un punto de partida, muy útil para dejarlos disponibles, pero no se ha preocupado de proporcionarles después la porción de felicidad que el género tradicionalmente les reservaba. La falta de una recompensa adecuada es por ello una de las lagunas más llamativas en el texto de Aquiles Tacio. Mientras para la pareja protagonista se abre un futuro de color de rosa, quedan ahí, en la imaginación del lector, flotantes como fantasmas a pesar de su relativa autonomía narrativa, los idealizados «amigos», siempre acompañantes pero nunca realmente acompañados. Por más que se les provea de una (siempre parcial) biografía, son seres por herencia eminentemente incompletos, subordinados y funcionales. Su carácter de auxiliares es determinante, por más que se les adorne de cualidades; sólo que no son socialmente desdeñables, como sí lo son los sirvientes.

Este análisis tiene aún una tercera etapa por delante, en la que se estudiará este tema en la novela de Heliodoro. Y será entonces el momento de llegar a unas conclusiones generales. 